\title{
Pengaruh Kualitas Layanan terhadap Kepuasan Pengunjung Agrowisata Bali Pulina untuk Membentuk Minat Kunjungan Ulang
}

\author{
NI NYOMAN ALIT PURNAMI, IGA. OKA SURYAWARDANI, \\ I KETUT SUAMBA
}

Program Studi Agribisnis Fakultas Pertanian Universitas Udayana

Jl. PB. Sudirman Denpasar 80232

e-mail: ninyomanalitpurnami@yahoo.com,

gungdani@gmail.com

\begin{abstract}
Effect of Service Quality on Satisfaction of Visitors of Bali Pulina Agro Tourism Forming their Interest in Repeating Visits.
\end{abstract}

Visitors perceptions of the quality of Bali Pulina's agrotourism services will give them satisfaction, which in turn will form the interest of visitors to re-visit. The research was conducted at Bali Pulina agrotourism. This study aims to analyze the effect of service quality (physical evidence, reliability, responsiveness, assurance, and empathy) on visitor satisfaction over Bali Pulina agro tourism and analyze the effect of visitor satisfaction on the interest to re-visit. Respondents in this study were tourists who had visited Bali Pulina agro tourism. The number of sample respondents was 80 respondents obtained based on the accidental sampling method. The model was designed based on the Structural Equation Modeling (SEM) approach based on Smart PLS version 3.0 which was analyzed using a computer program. The results showed that physical evidence had a significant effect on visitor satisfaction $(p=0.002)$. Reliability had a significant effect on visitor satisfaction $(\mathrm{p}=0.005)$. Capture had a significant effect on visitor satisfaction $(\mathrm{p}=0.040)$. Guarantee had a significant effect on visitor satisfaction $(p=0.001)$. Empathy had a significant effect on visitor satisfaction $(p=0.014)$. Visitor satisfaction had a significant effect on interests in repeat visits $(p=0,000)$. Based on the results of the study, Bali Pulina agrotourism is expected to be able to maintain and improve the quality of services, so that visitors feel satisfied and intend to make a repeat visit.

Keywords: agrotourism, service quality, satisfaction, repeat visits, PLS

\section{Pendahuluan}

\subsection{Latar Belakang}

Sektor pertanian merupakan sektor yang dominan dan merupakan tulang punggung perekonomian Indonesia. Menurut Utama (2015) pertanian merupakan potensi kuat yang dapat dikembangkan sebagai daya tarik yang dapat dinikmati oleh wisatawan nusantara maupun mancanegara. Rangkaian kegiatan pertanian dari budidaya 
sampai pascapanen dapat menjadi objek wisata yang memiliki daya tarik tersendiri bagi wisatawan yang berkunjung ke Indonesia (Sammeng, 2001). Indonesia yang kaya akan potensi dan sumberdaya mempunyai peluang yang sangat besar untuk dikembangkan terutama untuk industri pariwisata karena industri pariwisata mampu menghasilkan pendapatan yang tinggi sehingga mampu dijadikan sebagai modal dalam pembangunan baik tingkat lokal, regional, maupun nasional (Suryana, 2006). Banyak wilayah di Indonesia yang memiliki pesona alam yang menjadi tujuan wisatawan. Salah satunya adalah Provinsi Bali.

Provinsi Bali mempunyai banyak daerah yang menjadi destinasi wisata yang dapat dikunjungi oleh wisatawan (BPS, 2017). Menurut Suryawardani dan Wiranatha 2015 , bentang alam yang indah dan keindahan alam yang menakjubkan yang dimiliki oleh Bali menjadi daya dukung suksesnya atraksi wisata alam yang ada di Bali. Bali dikenal para wisatawan karena memiliki potensi alam yang amat indah antara lain, iklim yang tropis, hutan yang hijau, gunung, danau, sungai, sawah serta pantai indah. Peningkatan kualitas destinasi sangat diperlukan sebagai daya dukung keberhasilan wisata alam di Bali (Suryawardani, 2017). Salah satu daerah yang menjadi kunjungan wisatawan adalah Kabupaten Gianyar, yang mengandalkan sektor pertanian sebagai objek wisata. Kondisi ini membuat sektor pertanian menjadi salah satu produk alternatif yang dapat diandalkan dunia pariwisata khususnya agrowisata.

Salah satu agrowisata yang populer di kalangan wisatawan adalah agrowisata Bali Pulina, yang terletak di Kecamatan Tegallalang, Gianyar. Agrowisata Bali Pulina merupakan wisata alam kopi luwak dengan pemandangan alam sekitarnya yang indah dan menawan. Agrowisata Bali Pulina bukan merupakan satu-satunya perusahaan penyedia jasa agrowisata di wilayah Tegallalang. Adanya kecenderungan jumlah objek wisata yang semakin meningkat di wilayah Tegallalang akan meningkatkan persaingan industri wisata ke arah kompetitif dan membuat konsumen jasa wisata lebih mudah pindah ke perusahaan pesaing lain karena memiliki banyak alternatif objek wisata lain untuk dikunjungi (Supranto, 2001). Hal ini membuat tantangan persaingan usaha di lingkungan agrowisata Bali Pulina semakin terasa. Agrowisata Bali Pulina sebagai unit bisnis wisata, perusahaan harus banyak memperhatikan bagaimana cara memberikan layanan jasa agrowisata yang sesuai keinginan pasar agar mampu bersaing dengan kompetitornya.

Menurut Parasuraman, et al., (1990) dalam Tjiptono (2005), dimensi umum yang mewakili kriteria evaluatif pelanggan untuk menilai kualitas layanan terdiri dari bukti fisik, keandalan, daya tanggap, jaminan, dan empati. Penilaian pengunjung terhadap atribut-atribut kualitas layanan yang ada di agrowisata Bali Pulina adalah indikator untuk mengetahui layanan yang harus ditingkatkan kualitasnya. Pada penelitian ini, pengunjung agrowisata Bali Pulina menjadi fokus utama dalam penentuan suatu kebijakan karena keberhasilan dan keberlangsungan unit bisnis agrowisata ini sangat ditentukan oleh besar kecilnya jumlah kunjungan. Hal ini mengharuskan agrowisata Bali Pulina untuk selalu berusaha memperbaiki dan meningkatkan kualitas layanan jasa agrowisata agar pengunjung tertarik, merasa puas, dan mau berkunjung kembali di masa yang akan datang. 


\subsection{Tujuan}

Tujuan penelitian ini adalah sebagai berikut.

1. Untuk menganalisis pengaruh dimensi kualitas layanan (bukti fisik, keandalan, daya tanggap, jaminan, dan empati) terhadap kepuasan pengunjung agrowisata Bali Pulina.

2. Untuk menganalisis pengaruh kepuasan pengunjung terhadap minat untuk melakukan kunjungan ulang.

\section{Metode Penelitian}

\subsection{Lokasi dan Waktu Penelitian}

Penelitian ini dilakukan selama tiga bulan dari bulan Maret sampai April 2018 di agrowisata Bali Pulina yang beralamat di Jl. Banjar Pujung Kelod, Tegallalang Gianyar. Dasar pertimbangannya: (1) ramainya wisatawan yang berkunjung ke Agrowisata Bali Pulina, dan (2) belum pernah ada penelitian mengenai analisis pengaruh kualitas layanan terhadap kepuasan pengunjung di agrowisata Bali Pulina dan pihak agrowisata bersedia untuk memberikan izin untuk melakukan penelitian.

\subsection{Data dan Metode Pengumpulan Data}

Data dalam penelitian ini berupa data kualitatif dan kuantitatif, baik dari sumber primer maupun sekunder. Pengumpulan data pada penelitian ini dilakukan dengan dua metode yaitu, metode kepustakaan (library research) dan field research (observasi, wawancara langsung, kuesioner, dan dokumentasi).

\subsection{Populasi dan Sampel Penelitian}

Pada penelitian ini, yang menjadi populasi adalah wisatawan yang telah berkunjung ke Agrowisata Bali Pulina. Pengambilan sampel dalam penelitian ini menggunakan metode accidental sampling dengan jumlah sampel sebanyak 80 orang responden yang ditentukan secara sengaja (purposive).

\subsection{Variabel dan Analisis Data}

Variabel-variabel yang dianalisis dalam penelitian ini adalah:(1) Kualitas layanan (X) meliputi bukti fisik (X1), keandalan (X2), daya tanggap (X3), jaminan (X4) dan empati (X5); (2) Kepuasan pengunjung (Y1) dan (3) Minat kunjungan ulang (Y2). Analisis data dilakukan melalui pengujian hipotesis dalam model persamaan struktural (Structural Equation Modeling - SEM), yang dirancang sebelumnya. Alat analisis yang digunakan adalah program Smart-PLS versi 3.0. Hasil output dengan menggunakan sofwere Smart-PLS dianalisis secara deskriptif kualitatif

\section{Hasil dan Pembahasan}

\subsection{Karakteristik Responden}

Hasil penelitian menunjukkan jumlah responden sebagian besar berasal dari USA dan Australia, serta responden yang memiliki jenis kelamin laki-laki lebih banyak dari pada perempuan, dengan kelompok responden lebih banyak berusia 26-55 tahun dan memiliki pekerjaan yang paling banyak sebagai pegawai swasta. Informasi yang didapat pengunjung mengenai agrowisata Bali Pulina didapat dari teman/saudara dan pengujung yang datang ke agrowisata atas niat dari keinginan sendiri. 


\subsection{Analisis Konfirmatif}

Berdasarkan kerangka model yang dibangun dalam penelitian ini maka spesifikasi model persamaan struktural dapat dilihat pada gambar 1 sebagai berikut :

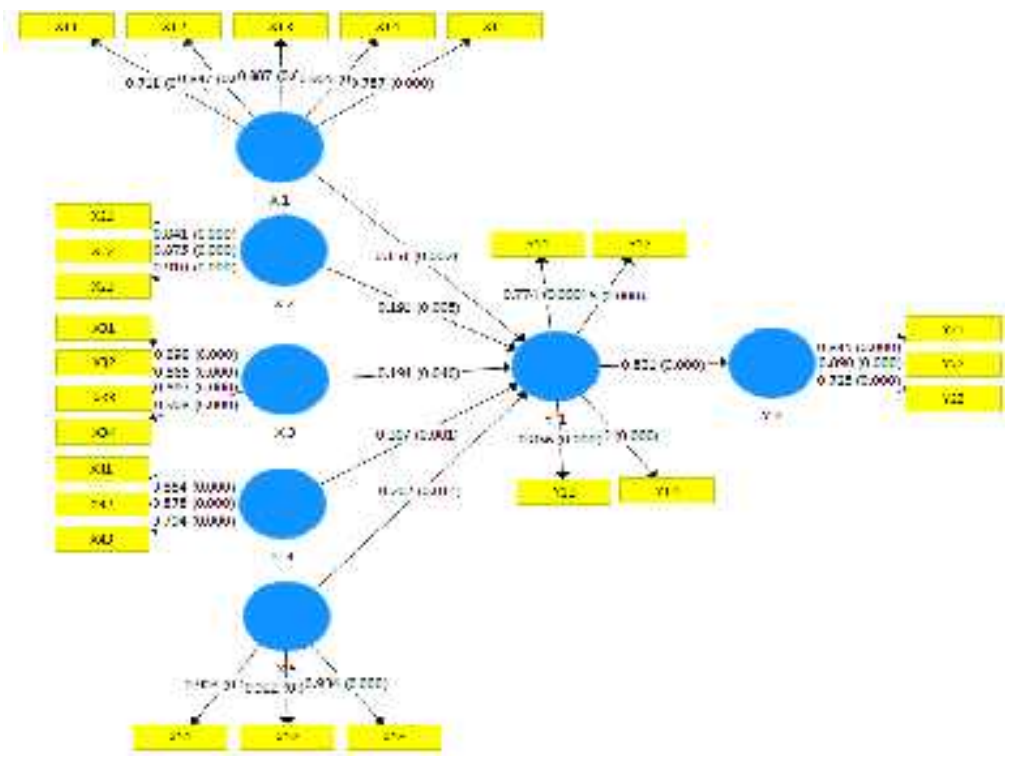

Gambar 1. Output Model Persamaan Struktural berbasis Smart PLS 3.0.

\subsubsection{Hasil Analisis Model Pengukuran (Outer/Measurement Model)}

Analisis pada model pengukuran (outer/measurement model) menunjukkan hubungan antara variabel dengan indikator pembentuknya (Ghozali, 2014). Terdapat enam jenis analisis pengukuran seperti diperlihatkan pada tabel-tabel berikut ini:

Tabel 1.

Uji Model Pengukuran dari Bukti Fisik

\begin{tabular}{llccrc}
\hline Kode & Pernyataan & Outer Loading & Standard Error & T-Statistics & \\
\hline X1.1 & Areal parkir & 0,711 & 0,071 & 9,331 & $* *$ \\
X1.2 & Kebersihan taman & 0,847 & 0,042 & 16,961 & $* *$ \\
X1.3 & Tempat-tempat yang digunakan & 0,887 & 0,042 & 22,657 & $* *$ \\
& untuk agrowisata & 0,905 & 0,021 & 42,605 & $* *$ \\
X1.4 & Kerapian penampilan karyawan & 0,787 & 0,052 & 16,849 & $* *$ \\
X1.5 & Peralatan yang digunakan & &
\end{tabular}

Keterangan :

** : Menyatakan signifikan

Sumber : Diolah dari data primer, (2018)

Berdasarkan tabel 1 indikator kerapian penampilan karyawan (X1.4) merupakan indikator dengan nilai outer loading tertinggi, hal ini mengindikasikan bahwa kerapian penampilan karyawan merupakan refleksi tertinggi bukti fisik agrowisata Bali Pulina, yang harus di pertahankan. Terlihat pula indikator area parkir (X1.1) pada variabel bukti fisik dianggap kurang dapat memberikan kepuasan bagi pengunjung karena memiliki nilai outer loading yang paling kecil, hal ini mengindikasikan tempat parkir di agrowisata sangat perlu ditata kembali. Hasil pengukuran pada variabel keandalan ditunjukkan pada tabel 2 . 
Tabel 2.

Uji Model Pengukuran dari Keandalan

\begin{tabular}{llcccc}
\hline Kode & Pernyataan & Outer Loading & Standard Error & T-Statistics \\
\hline X2.1 & Ketepatan waktu & 0,841 & 0,040 & 19,783 & $* *$ \\
& Pelayanan & & & & \\
X2.2 & $\begin{array}{l}\text { Kemampuan memberikan manfaat } \\
\text { edukasi }\end{array}$ & 0,875 & 0,044 & 18,894 & $* *$ \\
X2.3 & Informasi yang jelas & 0,901 & 0,034 & 25,464 & $* *$ \\
\hline
\end{tabular}

Keterangan :

** : Menyatakan signifikan

Sumber : Diolah dari data primer, (2018)

Tabel 2 menunjukkan bahwa indikator informasi yang jelas (X2.3) merupakan indikator yang paling kuat pengaruhnya dalam memberikan kepuasan bagi pengunjung agrowisata agrowisata Bali Pulina. Terlihat pula indikator ketepatan waktu pelayanan (X2.1) harus diperbaiki kinerjanya karena memiliki muatan faktor yang terkecil.Variabel laten ketiga selanjutnya yaitu daya tanggap dengan 4 indikator. Hasil analisis model pengukuran untuk variabel laten daya tanggap ditunjukan pada tabel 3 .

Tabel 3.

Uji Model Pengukuran dari Daya Tanggap

\begin{tabular}{llcccc}
\hline Kode & Pernyataan & Outer Loading & Standard Error & T-Statistics & \\
\hline X3.1 & $\begin{array}{l}\text { Kecepatan karyawan dalam } \\
\text { melayani pengunjung }\end{array}$ & 0,898 & 0,023 & 36,218 & $* *$ \\
X3.2 & $\begin{array}{l}\text { Ketanggapan karyawan dalam } \\
\text { membantu kesulitan pengunjung }\end{array}$ & 0,865 & 0,054 & 14,830 & $* *$ \\
X3.3 & $\begin{array}{l}\text { Kesediaan karyawan dalam } \\
\text { memberikan informasi }\end{array}$ & 0,897 & 0,037 & 25,739 & $* *$ \\
X3.4 & $\begin{array}{l}\text { Kesiapan karyawan dalam } \\
\text { merespon permintaan pengunjung }\end{array}$ & 0,908 & 0,033 & 27,742 & $* *$ \\
\hline Keterangan : & & & & \\
:** Menyatakan signifikan & & & & \\
Sumber & Diolah dari data primer, (2018)
\end{tabular}

Hasil model pengukuran variabel daya tangkap pada tabel di atas menunjukkan bahwa kesiapan karyawan dalam merespon permintaan pengunjung (X3.4) merupakan indikator dengan outer loading tertinggi, hal ini mengindikasikan bahwa kesiapan karyawan dalam merespon permintaan pengunjung merupakan refleksi tertinggi daya tanggap agrowisata Bali pulina, yang harus di pertahankan. Terlihat pula indikator ketanggapan karyawan dalam membantu kesulitan pengunjung (X3.2) merupakan indikator dengan outer loading terendah. Variabel laten keempat adalah jaminan hasil untuk model pengukuran variabel laten ini ditunjukkan pada tabel 4.

Tabel 4.

Uji Model Pengukuran dari Jaminan

\begin{tabular}{llcccc}
\hline Kode & Pernyataan & Outer Loading & Standard Error & T-Statistics \\
\hline X4.1 & Pengetahuan yang baik & 0,884 & 0,032 & 27,260 & $* *$ \\
X4.2 & Keramahan dan kesopanan & 0,878 & 0,044 & 19,805 & $* *$ \\
& karyawan & 0,798 & 0,064 & 12,344 & $* *$ \\
\hline
\end{tabular}

Keterangan :

** : Menyatakan signifikan

Sumber : Diolah dari data primer, (2018) 
Pada tabel 4 diketahui hasil model pengukuran variabel laten jaminan menunjukkan bahwa keramahan dan kesopanan karyawan (X4.2) merupakan indikator dengan outer loading tertinggi, sedangkan indikator keamanan dan kenyamanan (X4.3) merupakan indikator dengan outer loading terendah yang mengindikasikan bahwa keamanan dan kenyamanan merupakan refleksi terendah jaminan agrowisata pada pengunjung. Variabel laten kelima adalah empati, ditunjukkan pada tabel 5.

Tabel 5.

Uji Model Pengukuran dari Empati

\begin{tabular}{llcccc}
\hline Kode & Pernyataan & Outer Loading & Standard Error & \multicolumn{2}{l}{ T-Statistics } \\
\hline X5.1 & Perhatian personal karyawan & 0,903 & 0,042 & 21,397 & $* *$ \\
X5.2 & $\begin{array}{l}\text { Kesungguhan karyawan dalam } \\
\text { melayani pengunjung }\end{array}$ & 0,922 & 0,030 & 30,713 & $* *$ \\
X5.3 & $\begin{array}{l}\text { Kemauan karyawan untuk mendengar } \\
\text { dan menangani keluhan pengunjung }\end{array}$ & 0,934 & 0,027 & 34,253 & $* *$ \\
\hline
\end{tabular}

Keterangan :

** : Menyatakan signifikan

Sumber : Diolah dari data primer, (2018)

Berdasarkan hasil model pengukuran pada tabel 5 diketahui bahwa kemauan karyawan untuk mendengar dan menangani keluhan pengunjung (X5.3) merupakan indikator dengan outer loading tertinggi, yang menunjukkan refleksi tertinggi jaminan agrowisata Bali pulina, sedangkan indikator indikator dengan outer loading terendah yaitu perhatian personal karyawan (X5.1) yang mengindikasikan bahwa refleksi terendah pada variabel empati pada pengunjung agrowisata Bali Pulina yang hendaknya di tingkatkan lagi. Pada penelitian ini, variabel laten endogen yang terdapat pada model terdiri dari variabel kepuasan pengunjung dan variabel minat kunjungan ulang. Variabel kepuasan pengunjung dan minat kunjungan ulang dapat dilihat pada tabel berikut.

Tabel 6.

Uji Model Pengukuran dari Kepuasan Pengunjung

\begin{tabular}{|c|c|c|c|c|c|}
\hline Kode & Pernyataan & Outer Loading & Standard Error & T-Statistics & \\
\hline Y1.1 & $\begin{array}{l}\text { Kepuasan pengunjung atas atraksi } \\
\text { atau paket wisata yang dibeli }\end{array}$ & 0,774 & 0,054 & 14,208 & $* *$ \\
\hline Y1.2 & Kepuasan pengunjung atas fasilitas & 0,846 & 0,053 & 15,977 & $* *$ \\
\hline Y1.3 & Kepuasan pengunjung atas layanan & 0,856 & 0,047 & 18,053 & $* *$ \\
\hline Y1.4 & $\begin{array}{l}\text { Kepuasan pengunjung atas } \\
\text { keamanan dan kenyamanan }\end{array}$ & 0,880 & 0,034 & 25,899 & $* *$ \\
\hline
\end{tabular}

Keterangan :

** : Menyatakan signifikan

Sumber : Diolah dari data primer, (2018)

Berdasarkan tabel 6, indikator kepuasan pengunjung atas keamanan dan kenyamanan (Y1.4) memiliki kontribusi yang sangat besar terhadap kepuasan secara keseluruhan dan umumnya telah memenuhi harapan pengunjung agrowisata agrowisata Bali Pulina. Terlihat pula kepuasan pengunjung atas atraksi atau paket wisata yang dibeli (Y1.1) harus lebih diperhatikan oleh agrowisata Bali Pulina karena memiliki nilai outer loading yang terkecil. Pada variabel minat kunjungan ulang, ada tiga atribut yang digunakan dalam pengukurannya, nilai outer loading yang dimiliki masing-masing atribut pada variabel ini dapat dilihat pada tabel 7. 
Tabel 7.

Uji Model Pengukuran dari Minat Kunjungan Ulang

\begin{tabular}{llcccc}
\hline Kode & Pernyataan & Outer Loading & Standard Error & T-Statistics & \\
\hline Y2.1 & Keinginan berkunjung kembali & 0,845 & 0,050 & 16,928 & $* *$ \\
Y2.2 & $\begin{array}{l}\text { Minat mereferensikan kepada } \\
\text { orang lain }\end{array}$ & 0,890 & 0,024 & 36,947 & $* *$ \\
Y2.3 & $\begin{array}{l}\text { Minat untuk menjadikan } \\
\text { agrowisata pilihan utama }\end{array}$ & 0,725 & 0,054 & 13,341 & $* *$ \\
\hline
\end{tabular}

Keterangan :

** : Menyatakan signifikan

Sumber : Data primer (2018), diolah

Berdasarkan tabel 7, nilai outer loading tertinggi terdapat pada indikator minat mereferensikan kepada orang lain (Y2.2), artinya indikator minat mereferensikan kepada orang lain ini memiliki kontribusi atau pengaruh yang paling besar terhadap variabel minat kunjungan ulang. Adapun indikator yang memiliki nilai muatan faktor terendah berasal dari indikator minat untuk menjadikan agrowisata Bali Pulina sebagai pilihan utama objek agrowisata (Y2.3). Hal ini dikarenakan pengunjung kebanyakan ingin menikmati agrowisata lainnya.

\subsubsection{Hasil Model Struktural (Inner Model)}

Analisis pada inner atau structural model ditujukan untuk memeriksa hubungan antar variabel (Ghozali, 2014). Nilai-nilai koefisien jalur dari hubungan antar variabel pada model persamaan struktural yang dibangun diperlihatkan pada tabel 8. Nilai-nilai ini menunjukkan pengaruh-pengaruh langsung (direct effects) dari setiap variabel eksogen terhadap variabel endogen yang bersesuaian. Selain pengaruh langsung, dalam model persamaan struktural yang melibatkan hubungan antar variabel, juga bisa diperiksa pengaruh-pengaruh tak langsung (indirect effects) dari variabel eksogen terhadap variabel endogen melalui mediasi variabel laten yang lain. Memperhatikan kedua jenis pengaruh ini, maka interpretasi terhadap inner model dari persamaan struktural pada penelitian ini dibedakan seperti berikut:

Tabel 8.

Pengaruh Langsung Laten Eksogen terhadap Laten Endogen pada Inner Model

\begin{tabular}{|c|c|c|c|c|c|c|c|}
\hline Hip. & Var. Eksogen & & Var. Endogen & $\begin{array}{c}\text { Original } \\
\text { Sample }\end{array}$ & St. Dev & T Statistics & P Values \\
\hline $\mathrm{H} 1$ & Bukti Fisik & $\Rightarrow$ & $\begin{array}{l}\text { Kepuasan } \\
\text { Pengunjung }\end{array}$ & 0,154 & 0,050 & 3,101 & 0,002 \\
\hline $\mathrm{H} 2$ & Keandalan & $\Rightarrow$ & $\begin{array}{l}\text { Kepuasan } \\
\text { Pengunjung }\end{array}$ & 0,191 & 0,068 & 2,815 & 0,005 \\
\hline H3 & $\begin{array}{l}\text { Daya } \\
\text { Tanggap }\end{array}$ & $\Rightarrow$ & $\begin{array}{l}\text { Kepuasan } \\
\text { Pengunjung }\end{array}$ & 0,194 & 0,095 & 2,056 & 0,040 \\
\hline $\mathrm{H} 4$ & Jaminan & $\Rightarrow$ & $\begin{array}{l}\text { Kepuasan } \\
\text { Pengunjung }\end{array}$ & 0,307 & 0,090 & 3,392 & 0,001 \\
\hline $\mathrm{H} 5$ & Empati & $\Rightarrow$ & $\begin{array}{l}\text { Kepuasan } \\
\text { Pengunjung }\end{array}$ & 0,202 & 0,082 & 2,465 & 0,014 \\
\hline H6 & $\begin{array}{l}\text { Kepuasan } \\
\text { Pengunjung }\end{array}$ & $\Rightarrow$ & $\begin{array}{l}\text { Minat } \\
\text { Kunjungan } \\
\text { Ulang }\end{array}$ & 0,831 & 0,043 & 19,306 & 0,000 \\
\hline
\end{tabular}

Sumber: Diolah dari data primer, (2018) 
Memperhatikan nilai-nilai T Statistik pada tabel 8, maka secara jelas keenam hipotesis yang dikembangkan didukung secara nyata oleh hasil dari analisis model struktural yang dilakukan, dengan taraf signifikan 5\%. Kepuasan pengunjung secara nyata dipengaruhi oleh bukti fisik, keandalan, daya tangkap, jaminan dan empati. Di antara keenam dimensi kualitas layanan, jaminan dengan nilai sebesar 0,307 merupakan variabel yang paling berpengaruh terhadap kepuasan pengunjung agrowisata Bali Pulina. Variabel kepuasan pengunjung berpengaruh signifikan terhadap minat kunjungan ulang dengan nilai pengaruh sebesar 0,831. Semakin baik persepsi wisatawan terhadap kualitas layanan agrowisata Bali Pulina, semakin tinggi minat wisatawan untuk melakukan kunjungan ulang.

\subsubsection{Pengaruh tak Langsung Variabel Eksogen terhadap Variabel Endogen}

Terdapat beberapa jalur di mana sebuah variabel eksogen juga memiliki pengaruh tak langsung terhadap variabel endogen yang bersesuaian melalui mediasi variabel laten yang lain. Pada penelitian ini, variabel kepuasan pengunjung berperan sebagai mediator pengaruh seluruh dimensi kualitas layanan terhadap niat kunjungan ulang. Hal ini mengindikasikan adanya pengaruh tidak langsung dimensi kualitas layanan terhadap minat kunjungan ulang dengan dimediasi oleh variabel kepuasan pengunjung, maka dilakukan uji pengaruh tidak langsung dengan tabel 9.

Tabel 9.

Pengaruh Tidak Langsung Eksogen terhadap Laten Endogen pada Inner Model

\begin{tabular}{|c|c|c|c|c|c|c|}
\hline \multicolumn{3}{|c|}{ Variabel } & $\begin{array}{c}\text { Outer } \\
\text { loading }\end{array}$ & St. Dev & T Statistics & $\begin{array}{c}\mathbf{P} \\
\text { Values }\end{array}$ \\
\hline Eksogen & Mediasi & Endogen & & & & \\
\hline $\begin{array}{l}\text { Bukti } \\
\text { Fisik }\end{array}$ & $\Rightarrow$ Kepuasan & $\neg \begin{array}{r}\text { Minat Kunjungan } \\
\text { Ulang }\end{array}$ & 0,128 & 0,042 & 3,048 & 0,002 \\
\hline Keandalan & $\Rightarrow \begin{array}{l}\text { Kepuasan } \\
\Rightarrow \text { Pengunjung }\end{array}$ & 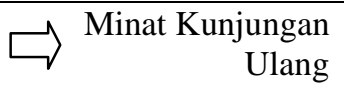 & 0,159 & 0,056 & 3,068 & 0,005 \\
\hline $\begin{array}{l}\text { Daya } \\
\text { Tanggap }\end{array}$ & $\Rightarrow \begin{array}{l}\text { Kepuasan } \\
\text { Pengunjung }\end{array}$ & $\Rightarrow \begin{array}{r}\text { Minat Kunjungan } \\
\text { Ulang }\end{array}$ & 0,162 & 0,079 & 1,986 & 0,042 \\
\hline Jaminan & $\Rightarrow \begin{array}{l}\text { Kepuasan } \\
\text { Pengunjung }\end{array}$ & $\neg \begin{array}{r}\text { Minat Kunjungan } \\
\text { Ulang }\end{array}$ & 0,255 & 0,076 & 3,270 & 0,001 \\
\hline Empati & $\Rightarrow$ Kepuasan & $\hookrightarrow \begin{array}{r}\text { Minat Kunjungan } \\
\text { Ulang }\end{array}$ & 0,168 & 0,068 & 2,462 & 0,014 \\
\hline
\end{tabular}

Sumber : Hasil analisis data responden, 2018

Pada model penelitian, terdapat lima hubungan tidak langsung seperti ditunjukkan pada tabel 9 memperlihatkan seluruh hubungan tak langsung. Lima pengaruh tak langsung masing-masing pengaruh tak langsung bukti fisik, keandalan, daya tanggap, jaminan, dan empati terhadap minat kunjungan ulang, melalui mediasi variabel laten kepuasan pengunjung, menunjukkan pengaruh yang signifikan dengan koefisien jalur sebesar 0,$128 ; 0,159 ; 0,162 ; 0,255$ dan 0,168 .

\subsubsection{Kelayakan dari Model Persamaan Struktural}

Sebelum dilakukan interpretasi terhadap hasil analisis model persamaan struktural penelitian ini, beberapa peneliti (Fornell \& Larcker, 1981; Chin et al., 2003; 
Hair et al., 2012; Henseler et al., 2009, dalam Suryawardani, 2018), merekomendasikan agar kelayakan model diperiksa. Tabel 10 memperlihatkan ukuran-ukuran yang lazim digunakan untuk menilai kelayakan model persamaan struktural yang dianalisis dengan metode Smart-PLS:

Tabel 10.

Uji Kelayakan Model Pengukuran Struktural

\begin{tabular}{|c|c|c|c|c|c|}
\hline Var Eksogen & $\begin{array}{c}\text { Jenis } \\
\text { Variabel }\end{array}$ & $\begin{array}{c}\text { Jml. } \\
\text { Indikator }\end{array}$ & $\begin{array}{l}\text { Composite } \\
\text { Reliability }\end{array}$ & $\begin{array}{c}\text { Average Variance } \\
\text { Extracted }\end{array}$ & $\mathrm{R}^{2}$ \\
\hline Bukti Fisik & Eksogen & 5 & 0,917 & 0,690 & $\mathrm{NA}^{\mathrm{a}}$ \\
\hline Keandalan & Eksogen & 3 & 0,908 & 0,767 & $\mathrm{NA}^{\mathrm{a}}$ \\
\hline Daya Tangkap & Eksogen & 4 & 0,940 & 0,796 & $\mathrm{NA}^{\mathrm{a}}$ \\
\hline Jaminan & Eksogen & 3 & 0,889 & 0,727 & $\mathrm{NA}^{\mathrm{a}}$ \\
\hline Empati & Eksogen & 3 & 0,943 & 0,846 & $\mathrm{NA}^{\mathrm{a}}$ \\
\hline Kepuasan & $\begin{array}{l}\text { Eksogen/ } \\
\text { Endogen }\end{array}$ & 4 & 0,905 & 0,706 & 0,896 \\
\hline Minat Kunjung Ulang & Endogen & 3 & 0,862 & 0,677 & 0,691 \\
\hline Rata-rata & - & - & - & $0,744^{\mathrm{b}}$ & 0,794 \\
\hline
\end{tabular}

Keterangan :

a : Nilai tidak tersedia karena laten berjenis eksogen

b : Rataan terbobot dengan bobot adalah jumlah indikator

Sumber : Diolah dari data primer, (2018)

Pada tabel 10 terlihat nilai-nilai koefisien determinasi $\left(\mathrm{R}^{2}\right)$ untuk setiap laten endogen. Merujuk Chin et al. (2003) dalam Suryawardani, (2018), variabel endogen dengan nilai $R^{2}$ berada pada rentang nilai 0,19 hingga 0,33 dikategorikan variabel yang dijelaskan secara lemah (weakly explained), berada pada rentang 0,33 hingga 0,67 dikategorikan variabel yang dijelaskan secara moderat, dan di atas nilai 0,67 dikategorikan terjelaskan secara kuat (substantially explained), maka kepuasan pengunjung dan minat kunjungan ulang adalah merupakan dua variabel endogen yang terjelaskan secara kuat oleh variabel-variabl eksogen yang bersesuaian.

Mengacu pada nilai Composite Reliability pada tabel 10, maka seluruh laten dalam model memiliki nilai Composite Reliability yang lebih besar dari nilai ambang 0,60 seperti dinyatakan (Chin et al, 2003 dalam Suryawardani, 2018). Hal ini menunjukkan bahwa seluruh indikator pada masing-masing variabel memiliki konsistensi internal yang bisa diandalkan.

\subsubsection{Hasil Analisis Fit Model}

Pada pengujian ini untuk menilai kelayakan model persamaan struktural secara utuh, maka nilai Goodness of Fit (GoF) dari model bisa dilakukan dengan merujuk formula yang diperkenalkan oleh Tenenhaus et al. (2005) sebagai berikut:

$$
\mathrm{GoF}=\sqrt{\overline{\text { Communality }} \times \overline{\overline{R^{2}}}}=\sqrt{\overline{A V E} \times \overline{R^{2}}}
$$

Pada persamaan di atas, $\overline{A V E}$ merupakan nilai rataan terbobot dengan bobot diperoleh dari jumlah indikator untuk setiap variable. GoF dari model dihitung sebesar 0,768 , sebuah ukuran yang melebihi nilai dari 0.50 untuk menyatakan model bisa diterima dan diintepretasikan, maka model PLS ini dinyatakan fit sehingga layak 
digunakan untuk menguji hipotesis penelitian.

Uji Goodness of Fit model PLS, juga dapat dilihat dari nilai nilai SMRM model. Model PLS dinyatakan telah memenuhi kriteria goodness of fit model jika nilai SRMR $<0,10$ dan model dinyatakan perfect fit jika nilai SRMR $<0,08$. Hasil uji Goodness of Fit model PLS menunjukkan bahwa nilai SRMR model PLS adalah sebesar 0,07, maka model PLS ini dinyatakan fit sehingga layak digunakan untuk menguji hipotesis penelitian.

\section{Simpulan dan Saran}

\subsection{Simpulan}

Berdasarkan hasil penelitian yang telah dilakukan dalam penelitian ini, maka dapat disimpulkan sebagai berikut.

(1) Pengaruh kualitas layanan terhadap kepuasan pengunjung:

Bukti fisik, keandalan, daya tanggap, jaminan, dan empati berpengaruh positif dan signifikan terhadap kepuasan pengunjung agrowisata Bali Pulina. Hal ini berarti bahwa semakin baik bangunan fisik agrowisata Bali Pulina maka kepuasan pengunjung di obyek wisata tersebut akan semakin tinggi, begitupun sebaliknya semakin buruk bangunan bukti fisik agrowisata Bali Pulina maka kepuasan pengunjung akan semakin rendah.

2) Kepuasan pengunjung berpengaruh positif dan signifikan terhadap minat kunjungan ulang ke agrowisata Bali Pulina. Hal ini berarti bahwa semakin tinggi kepuasan pengunjung agrowisata Bali Pulina maka minat pengunjung untuk mengunjungi kembali agrowisata Bali Pulina akan semakin tinggi, begitupun sebaliknya semakin rendah kepuasan pengunjung maka minat mengunjungi kembali akan semakin rendah.

\subsection{Saran}

Saran yang dapat disampaikan yaitu, pada variabel bukti fisik yang memiliki pengaruh terkecil dari variabel eksogen lainnya, jadi perlu diperhatikan lagi untuk dapat meningkatkan kepuasan pengunjung dan minat kunjungan ulang bagi pengunjung agrowisata Bali Pulina. Perbaikan yang harus diperhatikan yaitu, meningkatkan kualitas areal parkir dan meningkatkan kualitas peralatan yang akan digunakan pengunjung.

\section{Ucapan Terimakasih}

Ucapan terimakasih penulis tunjukkan kepada pihak agrowisata Bali Pulina dan semua pihak yang telah membentu pelaksanaan penelitian sehingga e-jurnal ini bisa diselesaikan dengan baik.

\section{Daftar Pustaka}

Badan Pusat Statistik Provinsi Bali. 2017. Ekonomi dan Perdagangan (Pariwisata). Diakses pada https://bali.bps.go.id/.pdf (diakses tanggal 1 Desember 2017).

Ghozali, I. 2014. Structural Equation Modeling MetodeAlternatif dengan Partial Least Square Aplikasi. Cetakan Keempat. Semarang: Penerbit Universitas Diponogoro.

Sammeng, A.M. 2001. Cakrawala Pariwisata. Cetakan pertama. Jakarta: Balai Pustaka. Suryana. 2006. Analisis Kepuasan Pengunjung dan Pengembangan Fasilitas Wisata Agro Studi Kasus di kebun Wisata Pasirmukti, Bogor. Jurnal Agro Ekonomi, Vol. 24 (1): 41-58). Bogor: Institut Pertanian Bogor. 
E-Jurnal Agribisnis dan Agrowisata $\quad$ ISSN:2301-6523 Vol. 8, No. 1, Januari 2019

Suryawardani, I G.A.O., and A.S. Wiranatha. 2015. Destination Marketing Strategy in

Bali through Optimizing the Potential of Local Products. E-Journal of Tourism.

Vol.1. No.1. (2014). Page: 35-49. ISSN: 2407-392X

Suryawardani, IG.A.AO., and Wiranatha, A.S., 2018. Evaluation of Marketing Strategy of Sanur Village Festival Based on Visitors"Behaviour. Internasional Journal of Applied Busniess and Economic Research. Vol 16, Number 2, 2018. Page: 216276. ISSN: 0972-7302.

Suryawardani, I G.A.O., A.S. Wiranatha, 1 K.G. Bendesa, M. Antara and Maria GravariBarbass. 2017. A Structural Model of Foreign Tourists' Loyalty in Nature-based Tourism in Bali. International Journal of Applied Business and Economic Research, Vol. 15, Number 9. 2018, page 195-215 (2017). ISSN 0972-7302.

Supranto. 2011. Pengukuran Tingkat Kepuasan Pelanggan. Jakarta: PT Rineka Cipta Tanenhaus, M. 2005. PLS Path Modeling: Computational Statistic and Data Analysis. Tjiptono F dan Candra G. 2005. Service, Quality, and Satisfaction. Yogyakarta: Andi. Utama, I. 2016. Agrowisata Sebagai Pariwisata Alternatif Indonesia. Cetakan Kedua. Yogyakarta: Deepublish. 